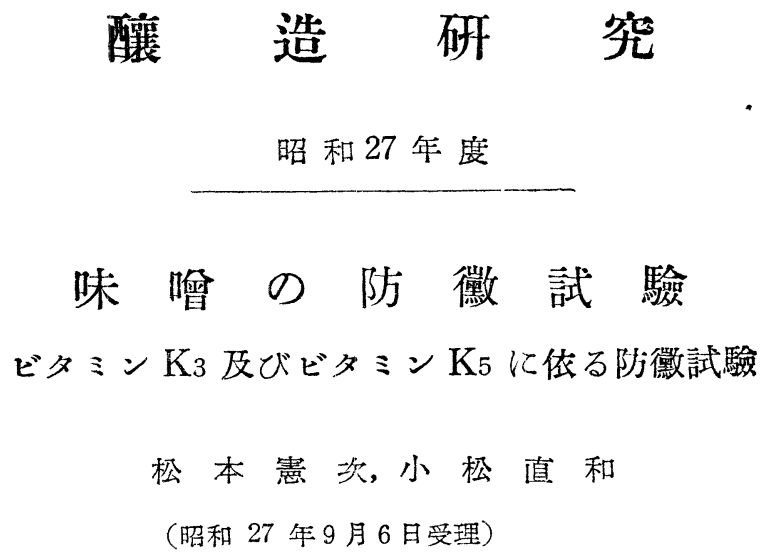

味唄の表面に発生する徽に就ては夏期などは殆ど市貶品として困つて居るのである。勿論過量食塩添加、

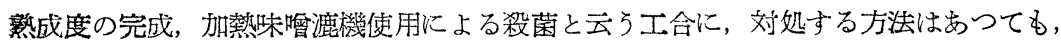

殆んど絶対的の防止方法は見当ら欢の゙ある。

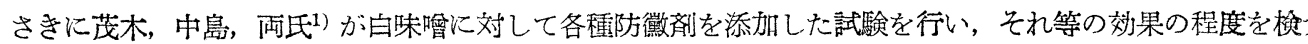
案した。

近時ビタミン $\mathrm{K}_{3}$ 攻び $\mathrm{K}_{5}$ が各種の微生物に抗菌力を現わすことは富安氏等の報告によつて明らかである。 佮, 中野政弘, 太田輝夫両氏はビタミン $\mathrm{K}_{3}$, ビタミン $\mathrm{K}_{5}$ の各種細菌に刘する抗菌性に関する研究を行い 更に佐藤喜吉. 井上幹夫両氏がビタミン $\mathrm{K}_{5}$ が味唓腐敗防止として効果を奏することを確認したのである。

其の他味噌の徽止方法又は徽繁殖の遅引门方法等として表面の被㠅膜として防徽剤塗付油紙の使用とか，客 器の塗料 (合成樹脂) 等が考究されているが未完成のものである。

著者等も味噲の徽止試験としてビタミン $\mathrm{K}_{3}$ 㝊び $\mathrm{K}_{5}$ を使朋して味噌の徽防止方法を試験したのて下に 其の経過を報告する。

\title{
実験
}

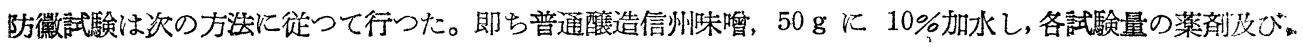

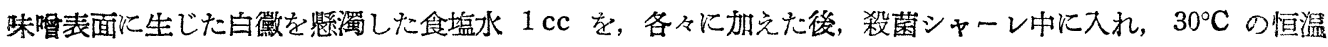
器内に静置し, 表面の徽の発生, 其の他を観察した。

\section{i) 防徽剂の稙類}

a) Vitamin $\mathrm{K}_{3}$ (2-Methyl-1.4-Naphtho quinone)

b) Vitamin $\mathrm{K}_{5}$ (2-Methyl-4-Amino-1-Naphthol-Hydrochloride)

c) Butyl para-hydroxybenzoate (試薬)

d) 同 上 (ボーキニン B)

\section{ii）防徵剂の添加}

防徽凪は各試料味既 $50 \mathrm{~g}$ に対する割合を以て，各添加量を算川们した。

\begin{tabular}{|c|c|c|c|c|c|c|c|}
\hline $\begin{array}{l}\text { 奏験 } \\
\text { 番号 }\end{array}$ & 防徽㶡の種類 & 添加割合 & $\begin{array}{l}50 \mathrm{~g} \text { 味噌中 } \\
\text { に含まれる } \\
\mathrm{mg} \text { 数 }\end{array}$ & $\begin{array}{l}\text { 実験 } \\
\text { 番号 }\end{array}$ & 防徽嵛の種類 & 添加割合 & $\begin{array}{l}50 \mathrm{~g} \text { 味噌中 } \\
\text { に含まれる } \\
\mathrm{mg} \text { 数 }\end{array}$ \\
\hline No. 1 & Vitamin $K_{3}$ & $8 / 100.000$ & 4 & No. 10 & vitamin $\mathrm{k}_{5}$ & $8 / 100.000$ & 4 \\
\hline No. 2 & /I & $1 / 10.000$ & 5 & No. 11 & "I & $1 / 10.000$ & 5 \\
\hline No. 3 & "I & $2 / 10.000$ & 10 & No. 12 & "I & $2 / 10.000$ & 10 \\
\hline No. 4 & $\prime \prime$ & $4 / 10.000$ & 20 & No. 13 & "I & $4 / 10.000$ & 20 \\
\hline No. 5 & $" \prime$ & $6 / 10.000$ & 30 & No. 14 & "I & $6 / 10.000$ & 30 \\
\hline No. 6 & "I & $8 / 10.000$ & 40 & No. 15 & "I & $8 / 10.000$ & 40 \\
\hline No. 7 & $\prime \prime$ & $1 / 1000$ & 50 & No. 16 & "I & $1 / 1000$ & 50 \\
\hline No. 8 & Vitamin $\mathrm{K}_{5}$ & $4 / 100.000$ & 2 & No. 17 & Butyl. P & $2 / 100.000$ & 1 \\
\hline No. 9 & II & $6 / 100.0 \Omega 0$ & 3 & No. 18 & II & $4 / 1000.000$ & 2 \\
\hline
\end{tabular}


尺ै

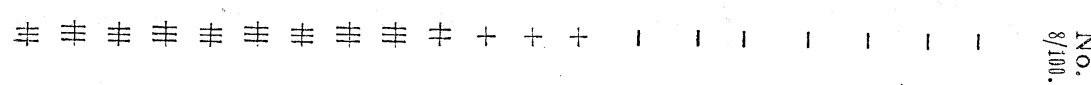

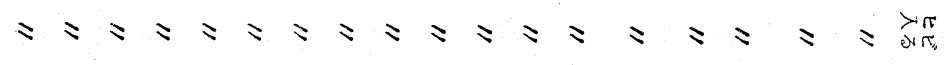

兽:

$\not \neq \neq \neq \neq \neq \neq \neq \neq \neq \neq \neq+++$

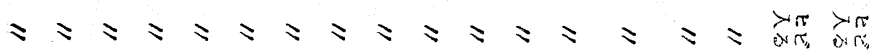

$\neq \neq \neq \neq \neq \neq \neq \neq \neq+++$

急

要告

$\neq \neq \neq \neq \neq \neq+1$

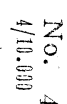

$\neq \neq \neq \neq+H+$\begin{tabular}{lllllll}
\hline & 1 & 1 & 1 & 1 & 1 & 1
\end{tabular}

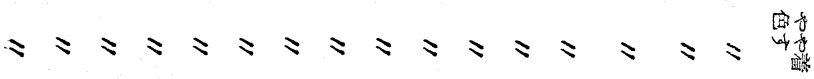

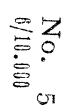

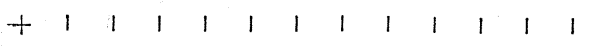

s s s s s s s s s s s s s

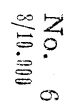

s s s s s s

농

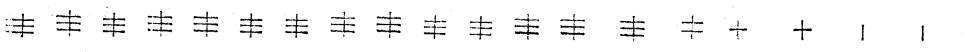

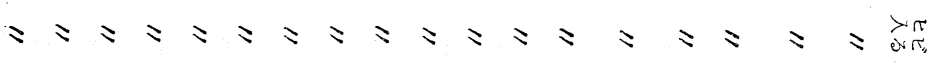

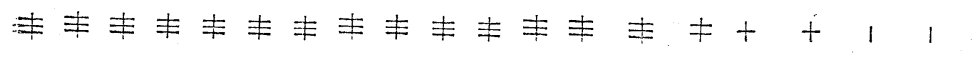

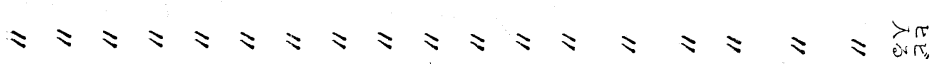

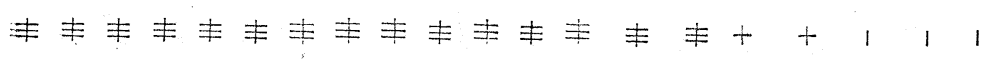

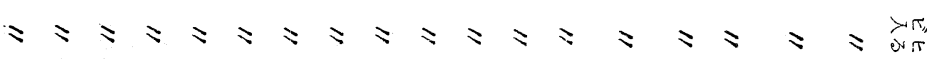

亭年

它证

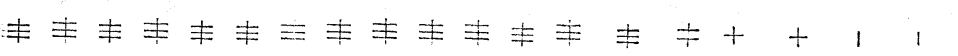

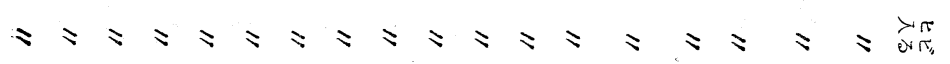

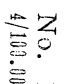

$\stackrel{\oplus}{\oplus}$

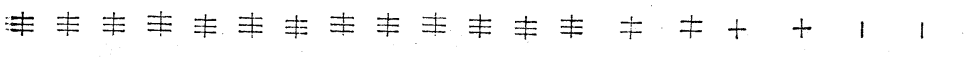

$s=s \leqslant s \leqslant s \leqslant s \leqslant s \leqslant s \leqslant s \leqslant s$

竞:

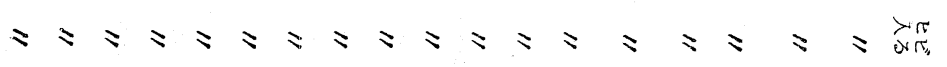

要

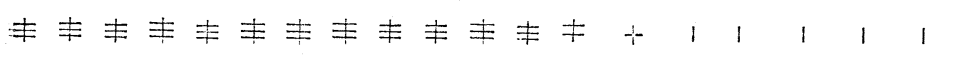

s s s s s s s s s s s s

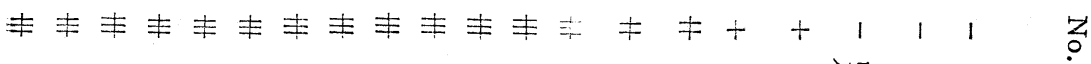

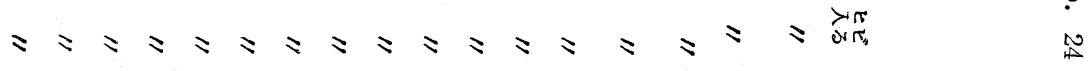

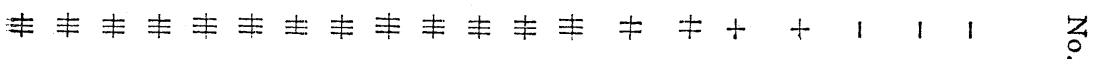

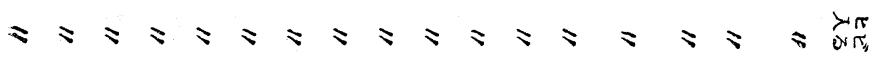




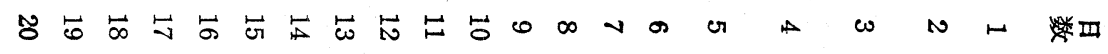

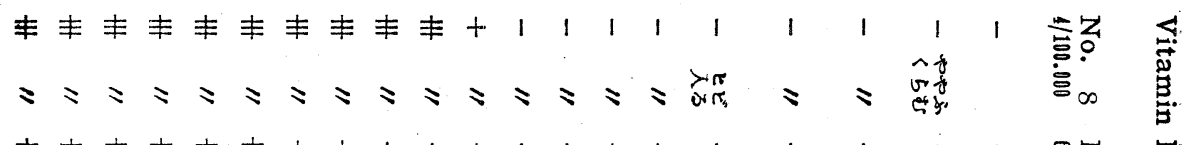

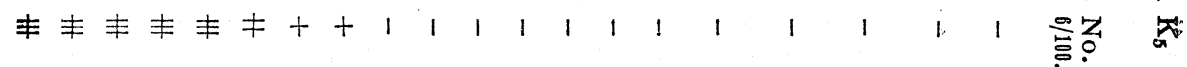

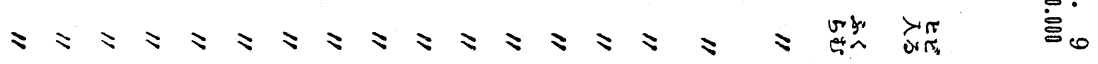

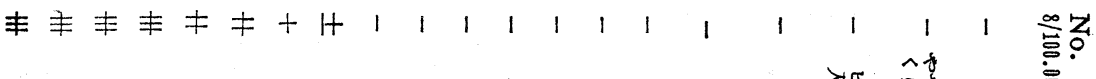

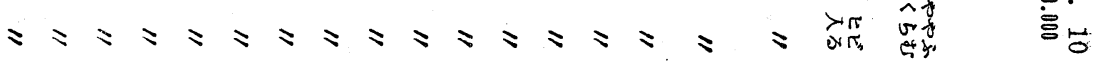

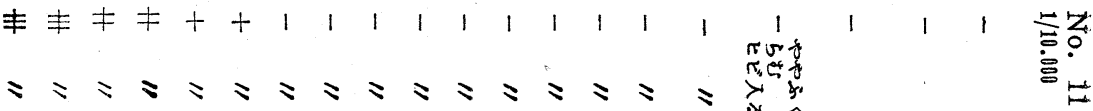

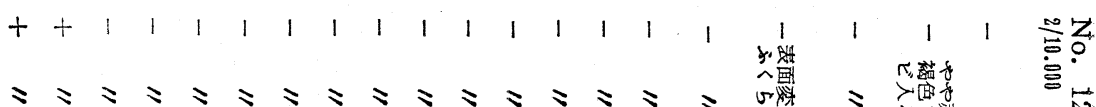

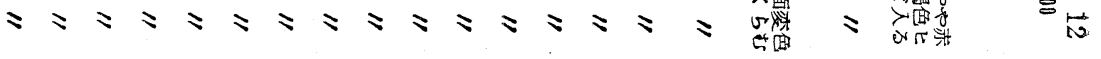

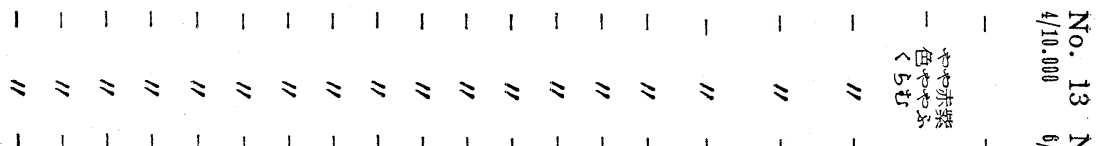

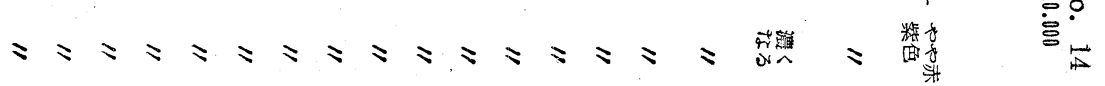

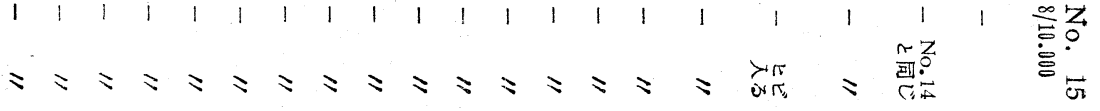

s s s s s s s s s

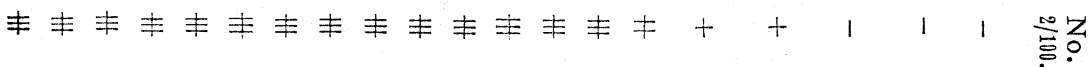

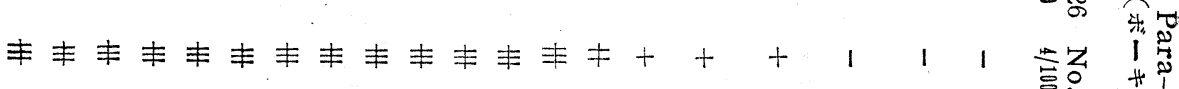

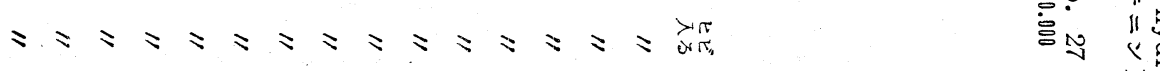

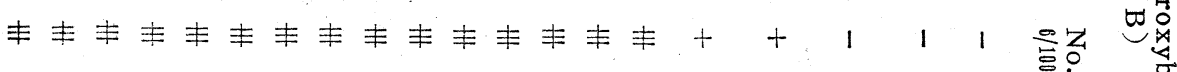

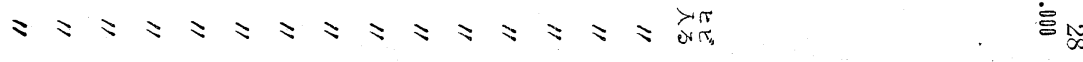

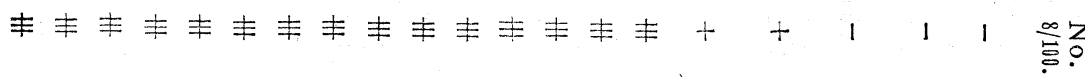

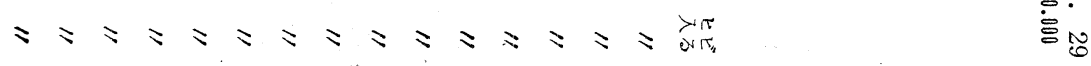

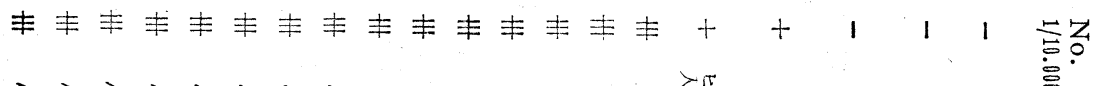

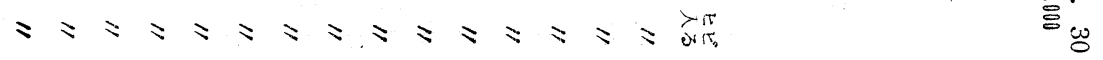

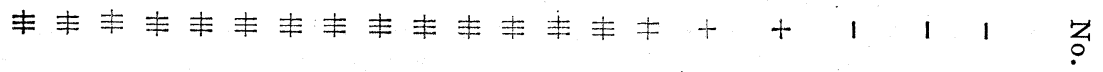

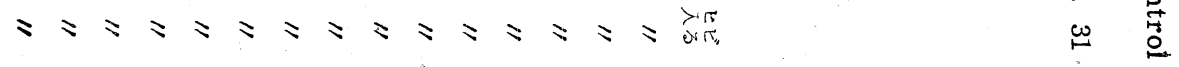

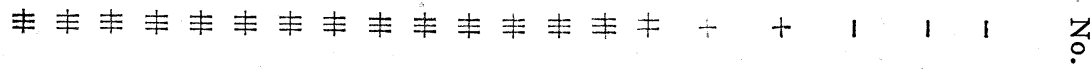

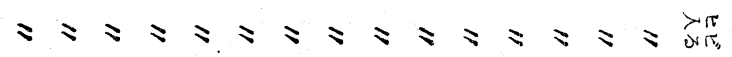




\begin{tabular}{|c|c|c|c|c|c|c|c|}
\hline $\begin{array}{l}\text { 実験 } \\
\text { 番号 }\end{array}$ & 防徽削の種類 & 添加割合 & $\begin{array}{l}50 \mathrm{~g} \text { 味噌中 } \\
\text { に含をれる } \\
\mathrm{mg} \text { 数 }\end{array}$ & $\begin{array}{l}\text { 実験 } \\
\text { 番号 }\end{array}$ & 防徽成の種類 & 添加割合 & 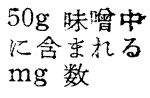 \\
\hline No. 19 & Butyl. P & $6 / 100.000$ & 3 & No. 26 & $\begin{array}{l}\text { Butyl. P } \\
(\text { ボーキニン B })\end{array}$ & $2 / 100.000$ & \\
\hline No. 20 & "I & $8 / 100.000$ & 4 & No. 27 & II & $4 / 100.000$ & \\
\hline No. 21 & "I & $1 / 10.000$ & 5 & No. 28 & "I & $6 / 100.000$ & \\
\hline No. 22 & alcohol (92\%) & $1 / 10.000$ & & No. 29 & $\prime \prime$ & $8 / 100.000$ & \\
\hline No. 23 & "I & $1 / 1000$ & & No. 30 & "I & $1 / 10.000$ & \\
\hline No. 24 & $\operatorname{Control}(\mathrm{A})$ & 徽蒜濁液 & 添 加 & No. 31 & Control (A) & 徽瞹濁液 & 添 加 \\
\hline No. 25 & $/ 1$ (B) & 同上 & 無添加 & No. 32 & /I (B) & 同上 & 無添加 \\
\hline
\end{tabular}

上記表に於いて, Vitamin $\mathrm{K}_{3}$ は alcohol. acetic acid 等の溶鼡に可溶であり, 又溶剤の濃度に低つて 溶解度が異るが，此の央験注 $92 \%$ alcohol を使用し，V. $\mathrm{K}_{3}$ の $2 \%$ alcohol 溶液を調製した。V. $\mathrm{K}_{5}$ は やや着色はして居たが，温湯に溶かし，2％水溶液とした。Butyl Para-hydroxybenzoate $0.5 \mathrm{cc}$ の $\mathrm{NaOH}(5 \%)$ に $100 \mathrm{mg}$ を溶解， $50 \mathrm{cc}$ に満たし $0.2 \%$ 水溶液とした。

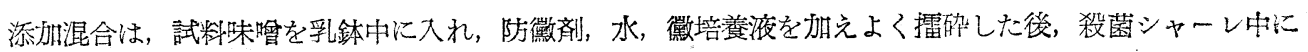
移した。

iii）観察

徽の発生状態の観察記録は次の符号によつて示した。

-…...徽の発生無し。

+…...部に徽の発生を見た状態。

H……点々と粗に徽が表面を蔽つた状態。

H……表面を密行徽が蔽つた状態。

その他の味噌の状態の变化は個々に就きその都度記載した。

\section{考察}

$\mathrm{K}_{5}$ 及び $\mathrm{K}_{5}$ の味噌に刘する防徽力は， $\mathrm{K}_{5}$ の方は $\mathrm{K}_{3}$ より強い様で佐藤喜吉博士，井上幹夫兩氏の味噌の

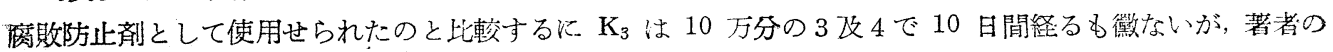
実験では 10 日目に 10 万分の 4 㗪が発生し 20 日閒でも徽ないのは 1 万分の 4 のものであつた。然し K の方は 10 万分の 8 のあのが 日目で発生し 20 日目で発生しないのは千分の 1 であつた。

パラオキシ安息香酸ブチールエステルをも比較試験したが殆ど効果を認めず，標準と何ら変らないて繁植 した。

$\mathrm{K}_{5}$ 攻 $\mathrm{K}_{3}$ を味䁚に添加すると，量を増すに従つて味噌自体の着色を増すので品質が劣る様になる。即ち 防徽力を与える量では味噌の色が好ましくないので，若し防徽剤とし使用するとせば表面のみ使用すること がよいと思われる。

結論

$\mathrm{K}_{3}$ 攻 $\mathrm{K}_{5}$ は共に味噌の防徽剤としては效果を認めた。 $\mathrm{K}_{5}$ は $\mathrm{K}_{3}$ よりは多少弱い様で $\mathrm{K}_{3}$ は酒精滨液 で 1 万分の 8 以上 $K_{3}$ は 1 万分の 4 以上を使用すれば 20 日閒前後は充分徽の発生を阻止する。唯味噌か清 色するのが火点である。

パラオキシ安息香酸ブチールエステルが防徽力は沿ど認められない。

(注) $\mathrm{K}_{3}$ 及放 $\mathrm{K}_{5}$ は武田薬品工業株式会社より寄贈せられたものである。

引用交献

i）茂木正利・中島茂次醄造学雑誌 Vol. 19 No. 11. 164 (昭 16)

On the Antiseptics for miso.

Vitamins $\mathrm{K}_{3}$ and $\mathrm{K}_{5}$ as the antiseptics for miso.

By K. Matsumoto and N. Komatsu.

(Received Sept. 7, 1952)

Summary

Both vitamins $K_{3}$ and $K_{5}$ were effective as the antiseptics for miso. Vitamin $K_{5}$ was more effective than $\mathrm{K}_{3}$. Addition of $0.08 \%$ Vitamin $\mathrm{K}_{3}$ or $0.04 \%$ Vitamin $\mathrm{K}_{5}$ as alcoholic Solution was found to be sufficient in preventing miso from putrefaction for 20 days. However, undesirable discoloration occurred by such addition. Butyl para-hydroxybenzoate was not effective as the antiseptic for miso. 